\title{
A Thermal Rating Calculation Approach for Wind Power Grid-Integrated Overhead Lines
}

\author{
Mengxia Wang ${ }^{1}$, Mingqiang Wang ${ }^{1, *}$, Jinxin Huang ${ }^{2}$, Zhe Jiang ${ }^{3}$ (i) and Jinyan Huang ${ }^{4}$ \\ 1 Key Laboratory of Power System Intelligent Dispatch and Control, Shandong University, Jinan 250061, \\ China; wangmx83@163.com \\ 2 State Grid of Technology College, Jinan 250002, China; huangmolin@163.com \\ 3 Electric Power Research Institute, State Grid Shandong Electric Power Company, Jinan 250003, China; \\ jiangzhe_edu@hotmail.com \\ 4 ZaoZhuang Power Supply Company of State Grid Shandong Electric Power Company, ZaoZhuang 264000, \\ China; wangph_2006@126.com \\ * Correspondence: wang0367@sdu.edu.cn; +86-531-8169-6124
}

Received: 7 April 2018; Accepted: 3 May 2018; Published: 12 June 2018

check for updates

\begin{abstract}
Currently, the rapid increase in wind power integration in power systems is resulting in an increasing power flow in the grid-integrated power transmission lines of wind farms. The wind power curtailment caused by the current limits (thermal ratings) of the wind power integration overhead lines (WPIOLs) is becoming increasingly common. Aiming at this issue, the influence of conductor heating on the loss of tensile strength (LOTS) and sag of a WPIOL was analyzed in this paper. Then a decision model is proposed for the thermal ratings of WPIOLs, which regards the minimized wind power curtailment as objective and introduces permissible cumulative LOTS and sag of the conductor as constraints. Based on this model, the thermal rating for a WPIOL can be decided to ensure the expected service life of the conductor and safe clearance. In addition, case studies are used to demonstrate that the proposed approach is capable of improving the conservatism of conventional thermal rating calculation and reducing the wind power curtailment by improving the utilization efficiency of WPIOLs.
\end{abstract}

Keywords: power system; wind power accommodation; overhead transmission line; thermal rating; loss of strength; sag

\section{Introduction}

The development of wind power generation has rapidly progressed in recent years, and the growth trend of the installation capacity of wind power is expected to continue. As reported by the Chinese government, the installed capacity of wind farms in China will reach 200 GW in 2020 [1]. However, the supporting power grid construction is relatively backward. The wind power generated by some newly established wind farms or wind turbines have to be integrated with power systems via existing transmission lines. Therefore, the transfer capability of the wind power integration overhead line (WPIOL) is becoming one of the restricting factors of wind power accommodation [2-4]. Although speeding up the power grid construction is effective for relieving the tension of transfer capability, the construction period of a power grid is much longer than that of wind farms, and the fluctuation nature of wind power often entails the under-utilization of transmission components. Therefore, exploiting the potential transfer capability of the existing transmission lines is the preferred way to accommodate wind power.

In principle, the thermal limit on power transfer capability of a transmission line is determined by its maximum allowable sag and the loss of tensile strength (LOTS) $[5,6]$. However, in practice, the 
thermal limit is represented by a maximum permissible temperature (MPT), and for convenience and security, a unified MPT is always conservatively suggested for overhead conductors to ensure that even though the conductor continuously operates on the MPT for thousands of hours, the LOTS of the conductor will only be slightly affected [7,8]. Based on the specified MPT, the static thermal rating (STR) calculation further converts the MPT limit of transmission lines into the current limit (thermal rating) by solving the heat balance equation (HBE) under the conservative ambient weather assumptions [9]. The STR has the advantages in easy calculation and utilization, but the STR is also obvious conservative which is not conductive to wind power accommodation. To exploit the transfer capability of WPIOLs, the dynamic thermal rating (DTR) technique, which calculates the thermal ratings of transmission lines based on the measured meteorological data (including ambient temperature, wind speed \& direction, and solar insolation) [10,11], has been applied on WPIOLs. As reported in [12-16], DTR can provide a much larger thermal rating than STR in most cases, thus significantly benefitting wind power accommodation. However, compared with STR, DTR has certain disadvantages: (1) additional facilities need to be equipped to measure the weather data and transfer them to operators, adding to the cost of operation \& maintenance of the power system; (2) it is not convenient for operators to use time-varying thermal ratings of transmission lines to make dispatch decisions or set the relay protections [17,18].

When the overhead lines are heated in service, the annealing effect will cause conductor loss of tensile strength (LOTS). For an operational aluminum conductor steel reinforced (ACSR) conductor, the LOTS is a cumulative process, and the acceptable cumulative LOTS of its aluminum part is approximately $10 \%$ during the entirety of the expected service life of the conductor [19]. The LOTS is not only related to the operational temperature of the conductor but also the temperature duration, i.e., the violation on the MPT in a short time that is harmless to the expected service life of the conductor is acceptable; thus, the transfer capability of the conductor tended to be underestimated when the MPT is regarded as a rigid restriction. Therefore, to exploit the transfer capability of the conductor in an emergency condition, in many countries, the emergency rating is practically used under an elevated temperature for short time. For example, the emergency thermal rating of an ACSR conductor in USA is calculated below $125^{\circ} \mathrm{C}$, and the permissible sustained time is $15 \mathrm{~min}$ [6], whereas the emergency thermal rating in China is calculated under $90^{\circ} \mathrm{C}$, and the permissible sustained time is $30 \mathrm{~min}$.

Owing to the high volatility of wind speed, it is impossible for a wind turbine to sustain a certain power output for a long time. In China, the average number of the annual equivalent full power hours of wind farms is only approximately 2000 [3]; hence, the power flow and temperature of WPIOLs is also highly fluctuating. Therefore, the thermal ratings for WPIOLs have the potential to be improved by considering the cumulative process of the LOTS of a conductor and by directly regarding the LOTS and the sag limit as the restriction of thermal rating calculation instead of calculating the thermal ratings under the specified MPT. To this end, the contributions of this paper are as follows:

(1) A new model is proposed to estimate the thermal ratings of WPIOLs. The model converts the thermal rating calculation into an optimization problem by regarding the maximum wind power integration as objective and the allowable cumulative LOTS and sag limits of the conductor as constraints, thereby revealing the essence of the thermal limit on power transfer capability of WPIOLs and benefiting the improvement of the utilization efficiency of WPIOLs.

(2) A heuristic algorithm is presented to solve the model, in which the cumulative process of the LOTS with the variation in the temperature of the conductor under every tested thermal rating is calculated, and the clearances of the spans are checked. It can not only find a thermal rating satisfying the constraints of the LOTS and clearance but also identify the restriction factor for the further improvement of the thermal rating.

(3) The proposed thermal rating calculation approach was applied on a practical WPIOL under different wind conditions for verification. The calculation results showed that the decided thermal rating of the WPIOL was significantly improved compared with the conventional STR. 
The remainder of this paper is organized as follows. Section 2 introduces the mathematical expressions of the relationship between current and temperature of the conductor, the temperature and LOTS of the conductor, and the temperature and tension of overhead lines. Section 3 presents the thermal rating decision model and its solution algorithm. Section 4 analyzes the simulation results, and Section 5 draws the conclusions.

\section{The Mathematical Expressions of the Electro-Thermal-Mechanical Associated Relationships of the Conductor}

For an operating overhead transmission line, there are physical associated relationships among its current, temperature, tension and LOTS. The electro-thermal-mechanical associated relationships of the overhead transmission lines can be characterized by Figure 1. The detailed thermal, mechanical, and LOTS models of overhead conductors shown in Figure 1 and the analysis of the temperature variation and cumulative LOTS of a WPIOL will be shown in following subsections.

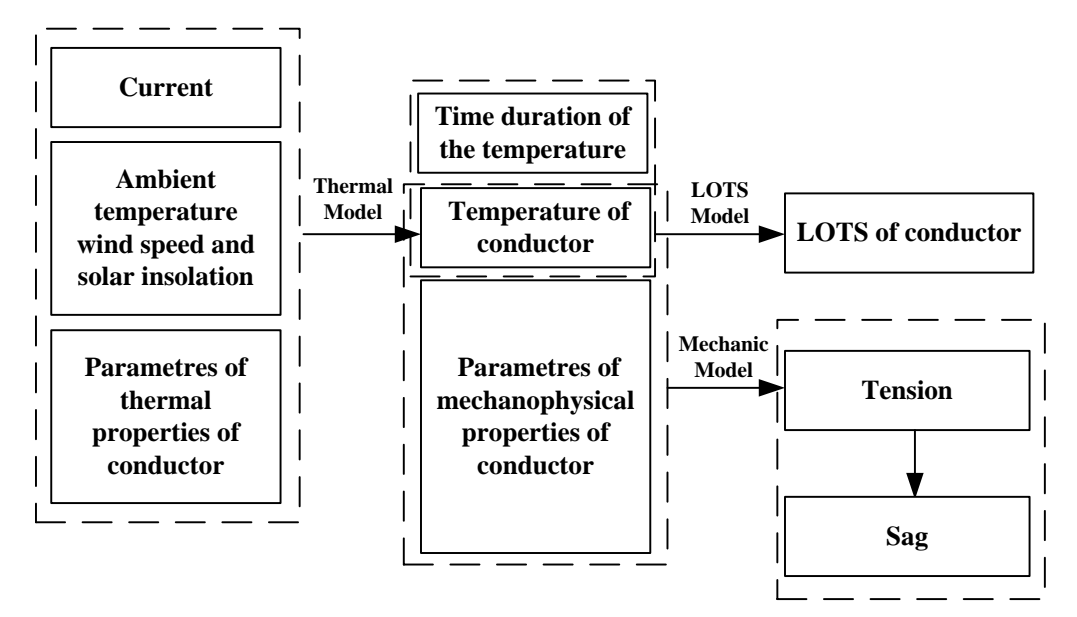

Figure 1. Electro-thermal-mechanical associated relationships of overhead transmission line.

\subsection{Thermal Model of Conductor}

For an operating overhead line $l$, its temperature $\left(T_{l}\right)$ changes with its current $\left(I_{l}\right)$ and meteorological environment. The relationship between the current of the conductor and temperature under a thermal steady state can be described by the following heat balance equation (HBE; The corona heating and evaporative heat loss are ignored) [20,21]:

$$
q_{l}^{\text {joule }}(t)+q_{l}^{\text {solar }}(t)-q_{l}^{\text {conv }}(t)-q_{l}^{\text {rad }}(t)=0
$$

Equation (1) is the generalized expression of the HBE, where $q_{l}^{\text {joule }}, q_{l}^{\text {solar }}, q_{l}^{\text {conv }}$, and $q_{l}^{\text {rad }}$ represent heat produced by current, heat absorbed from solar insolation, heat loss caused by convection, and heat loss caused by thermal radiation, respectively. They are all time-dependent and their detailed expressions are as follows:

$$
\begin{gathered}
q_{l}^{\text {joule }}(t)=I_{l}^{2}(t) R_{l}^{r e f}\left[1+\alpha\left(T_{l}(t)-T_{l}^{r e f}\right)\right], \\
q_{l}^{\text {solar }}(t)=\beta Q_{s e}(t) A, \\
q_{l}^{\text {conv }}(t)=A_{l}^{\text {conv }}\left(T_{l}(t)\right)\left(T_{l}(t)-T_{l}^{a m b}(t)\right), \\
q_{l}^{\text {rad }}(t)=A_{l}^{\text {rad }}(t)\left[\left(273+T_{l}(t)\right)^{4}-\left(273+T_{l}^{\text {amb }}(t)\right)^{4}\right] .
\end{gathered}
$$


Equation (2) is the detailed expression of the joule heating of the overhead line $l$. The resistance-temperature effect of the conductor is considered by multiplying the term $\left[1+\alpha\left(T_{l}(t)-T_{l}^{r e f}\right)\right]$. Equation (3) denotes the solar heating of the overhead line $l$ which is related to the solar radiation $Q_{s e}(t)$. Equation (4) shows the heat loss caused by convection, which is calculated using $A_{l}^{c o n v}$ and multiplying the difference between the conductor temperature and ambient temperature. Here, $A_{l}^{\text {conv }}$ is the convective coefficient related to the temperature of conductor, wind speed and direction. Equation (5) shows the heat loss caused by thermal radiation, which is calculated using $A_{l}^{\text {rad }}$ and multiplying the difference between the biquadrates of the absolute conductor temperature and the absolute ambient temperature. Here, $A_{l}^{\text {rad }}$ is the radiation heat transfer coefficient. The detailed calculation formulas of $A_{l}^{\text {conv }}$ and $A_{l}^{\text {rad }}$ can be found in the CIGRE standard [17].

Based on Equation (1), the thermal rating is conventionally calculated under the specified MPT and meteorological data (ambient temperature, wind speed, wind direction, and solar insolation) by using:

$$
I_{l}^{T R}=\sqrt{\frac{q_{l}^{\text {conv }}\left(T_{l}^{\max }\right)+q_{l}^{\text {rad }}\left(T_{l}^{\max }\right)-q_{l}^{\text {solar }}}{R_{l}^{r e f}\left[1+\alpha\left(T_{l}^{\max }-T_{l}^{r e f}\right)\right]}}
$$

where $T_{l}^{\max }$ is the specified MPT of the conductor.

In addition, Equation (1) can also be used to calculate the steady-state temperature of overhead line $l$ based on the given current and meteorological conditions. Figure 2 shows the annual duration curve of the temperature of a WPIOL based on the hourly current in a Chinese wind farm in a year. The installation capacity of the wind farm is $99 \mathrm{MW}$, and the conductor type of the WPIOL is ACSR 300/40. The weather condition is conservatively assumed as follows: the ambient temperature is $35^{\circ} \mathrm{C}$, wind speed is $0.5 \mathrm{~m} / \mathrm{s}$ (perpendicular to the conductor), and solar insolation is $1000 \mathrm{w} / \mathrm{m}^{2}$. For comparison, the annual temperature duration curve of two other types of conductors (ACSR 210/35 and ACSR 240/40) are used, as shown in Figure 2. Table 1 shows the temperature variation range.

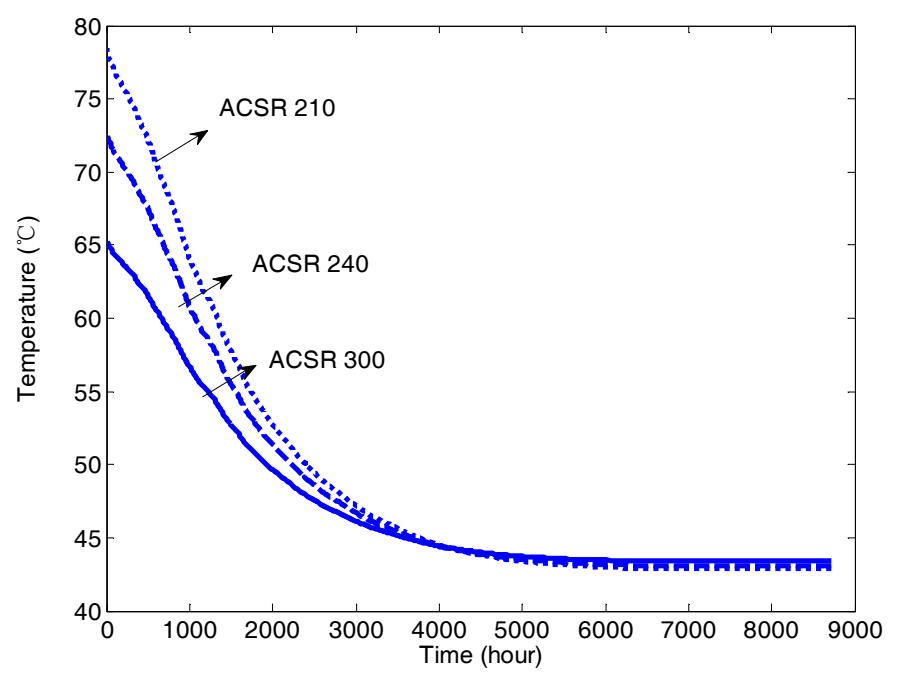

Figure 2. Annual temperature duration curve of a WPIOL.

Table 1. Relevant information of Figure 2.

\begin{tabular}{cccc}
\hline & ACSR210 & ACSR240 & ACSR300 \\
\hline Duration for over $60^{\circ} \mathrm{C}(\mathrm{h})$ & 1333 & 1067 & 656 \\
Temperature variation range $\left({ }^{\circ} \mathrm{C}\right)$ & {$[42.9,78.5]$} & {$[43.1,72.6]$} & {$[43.4,65.3]$} \\
\hline
\end{tabular}

As shown in Figure 2 and Table 1, the duration for the temperature over $60{ }^{\circ} \mathrm{C}$ (corresponding to the heavy loading condition) is only about $1000 \mathrm{~h}$, indicating that the temperature of the WPIOL 
also has a noticeable fluctuation property such as wind power. Moreover, with the increase in the cross-section of the conductor, the operational temperature decreased under the same loading condition due to the smaller resistance and larger heat radiation area which causes a smaller joule heat under the same current and greater heat losses of convection and thermal radiation.

\subsection{LOTS Model of Conductor}

For an ACSR, the tensile strength of the steel core is not affected by a temperature below $250{ }^{\circ} \mathrm{C}$; however, the aluminum wires would gradually anneal during the operational process, leading to the cumulative LOTS of the aluminum conductor. The LOTS is related to the operational temperature of the conductor and duration, based on numerous test results. Morgan derived the LOTS model, which can characterize the relationships between the LOTS percentage of different conductor types (copper, aluminum, and aluminum alloy) and their operational temperatures. The LOTS model can be expressed by the following equations [22,23]:

$$
\begin{gathered}
W=W_{a}\left\{1-\exp \left[-\exp \left(a+m \ln d^{t}+b T_{l}+c \ln (\lambda / 80)\right)\right]\right\}, \\
\lambda=100\left[1-\left(D_{w} / D_{0}\right)^{2}\right],
\end{gathered}
$$

where, $d^{t}$ represents the duration of temperature $T_{l}$ for aluminum conductor and $W_{a}=56, a=-8.3$, $b=0.035, c=9$, and $m=0.285$. Parameter $\lambda$ represents the influence of the cold work degree of an aluminum wire on its LOTS. According to the LOTS model (7), the cumulative LOTS of an operational WPIOL with the changing temperature in $N^{H}$ hours can be calculated as follows:

(1) Set $i=1$ and $d^{t}=1$. Calculate the temperature of the WPIOL in the $i$ th hour $\left(T_{l}(i)\right)$ by using Equation (1), then calculate the hourly percentage LOTS $(W(i))$ by using Equation (7).

(2) Set $i=i+1$. Calculate $T_{l}(i)$ by using Equation (1), then calculate the equivalent time $\left(t_{\text {equ }}\right)$ that can yield the LOTS $W(i-1)$ under $T_{l}(i)$ as follows:

$$
t_{\text {equ }}=\exp \left(\ln \left(\ln \left(\frac{1}{1-W(i-1) / W_{a}}\right)-\left(a+b T_{l}(i)\right)\right) / m\right)
$$

(3) Set $d^{t}=t_{\text {equ }}+1$ and calculate the cumulative LOTS $W(i)$ under $T_{l}(i)$ by using Equation (7).

(4) If $i=N^{H}$, the calculation procedure is completed, otherwise return to step (2) and continue.

Based on the calculation procedure, the calculation results of the cumulative LOTS of the conductor types specified in 2.1 under the same weather assumptions are shown in Table 2 (the historical two-year hourly current of the wind farm are used repeatedly to simulate the cumulative LOTS during different time spans).

Table 2. Cumulative LOTS of a WPIOL with different conductor types.

\begin{tabular}{cccc}
\hline Cumulative LOTS & ACSR210 & ACSR240 & ACSR300 \\
\hline The 1st year & $1.78 \%$ & $1.57 \%$ & $1.38 \%$ \\
5 years & $2.79 \%$ & $2.47 \%$ & $2.17 \%$ \\
10 years & $3.37 \%$ & $2.99 \%$ & $2.62 \%$ \\
20 years & $4.75 \%$ & $4.22 \%$ & $3.71 \%$ \\
30 years & $6.28 \%$ & $5.58 \%$ & $4.91 \%$ \\
\hline
\end{tabular}

As shown in Table 2, the ACSR210, which has the greater operational temperature, also has the greater cumulative LOTS, whereas the ACSR300 has the least cumulative LOTS, and the total cumulative LOTS of the applied conductor ACSR300 in the expected service life (30 years) is no more than $5 \%$, indicating that the WPIOL still has potential transfer capability to accommodate wind power. 
Figure 3 shows the detailed cumulative process of LOTS in the first year.

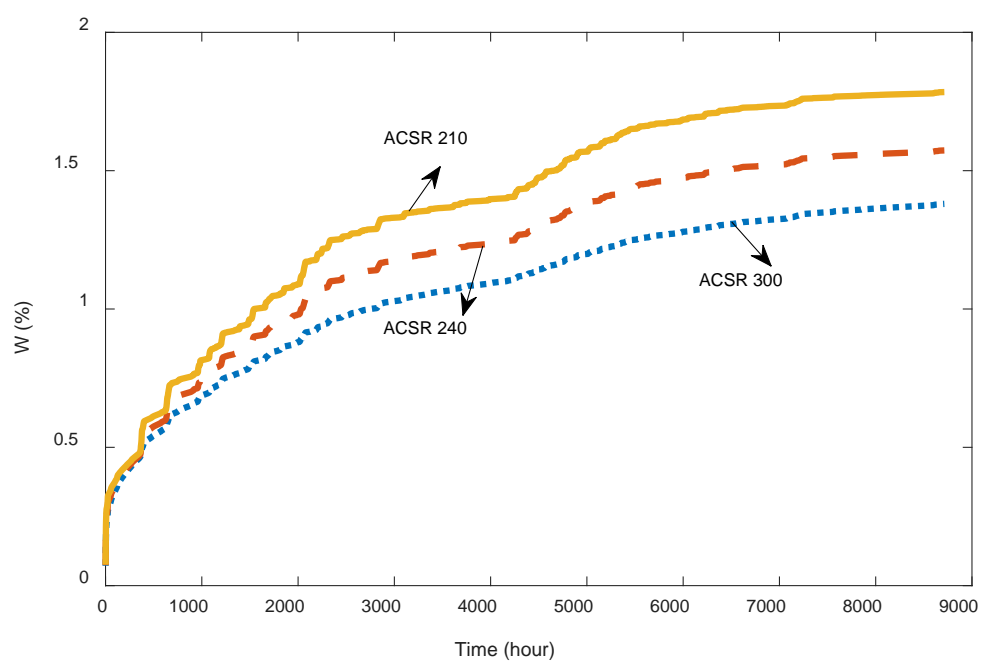

Figure 3. Annual LOTS curve of a WPIOL.

As shown in Figure 3, the cumulative process of LOTS is not stationary due to the temperature fluctuation. Besides, the temperature time duration $d^{t}$ is determined by the employed data resolution of the WPIOL's current and temperature (minutely, hourly or daily) in the simulation. Theoretically, the higher data resolution is employed the more accurate LOTS simulation result can be obtained. However, in general, the operation on the elevated temperature in several minutes does not lead to considerable LOTS (that is why the conductor is allowed to continuously operate tens of minutes on an elevated temperature in many counties' criterions). Therefore, the average hourly temperature of WPIOL is available for the simulation to give the valuable LOTS results.

\subsection{Mechanical Model of Overhead Lines}

Owing to the mechanophysical properties of the ACSR conductor (e.g., thermal expansion and elasticity), the tensile forces and sags of the spans are also related to the conductor temperature. According to the ruling span method, the relationship between the horizontal tensile stress and temperature can be characterized by the conductor state change equation (CSCE). Under the conservative weather condition specified in Section 2.1, the CSCE can be written as follows (the influences of wind and icing can be ignored under the specified weather condition) [24]:

$$
\sigma_{l, k}^{(m)}-\frac{E\left(m_{c} g\right)^{2}\left(s_{l, k}^{r}\right)^{2}}{24\left(\sigma_{l, k}^{(m)}\right)^{2} A^{2}}=\sigma_{l, k}^{(0)}-\frac{E\left(m_{c} g\right)^{2}\left(s_{l, k}^{r}\right)^{2}}{24\left(\sigma_{l, k}^{(0)}\right)^{2} A^{2}}-\varepsilon E\left(T_{l, k}^{(m)}-T_{l, k}^{(0)}\right),
$$

where the ruling span length of the $k$ th tensioning section can be calculated by:

$$
s_{l, k}^{r}=\sqrt{\frac{\sum_{b=1}^{N^{b}} s_{l, k, b}^{3}}{\sum_{b=1}^{N^{b}} s_{l, k, b}}},
$$

where $\sigma_{l, k}^{(0)}$ and $T_{l, k}^{(0)}$ are the horizontal tensile stress and conductor temperature of the tensioning section $k$ in overhead line $l$ at the initial state, respectively. They are the corresponding tensile stress and ambient temperature when the overhead line is initially stringed, and $\sigma_{l, k}^{(m)}$ is the unknown tensile 
stress of the tensioning section $k$ at state $m$, with conductor temperature $T_{l, k}^{(m)}$. By using CSCE, $\sigma_{l, k}^{(m)} \mathrm{can}$ be calculated, and then the lowest point of the sag (point $o$ in Figure 4) in the $b$ th span (span $A B$ in Figure 4 ) of the tensioning section $k$ can be calculated by

$$
f_{l, k, b}^{o}=\frac{m_{c} g a_{e}^{2}}{8 A \sigma_{l, k}^{(m)}},
$$

where:

$$
a_{e}=s_{l, k, b}+2 A \sigma_{l, k}^{(m)} \cdot h_{l, k, b} /\left(m_{c} g \cdot s_{l, k, b}\right) .
$$

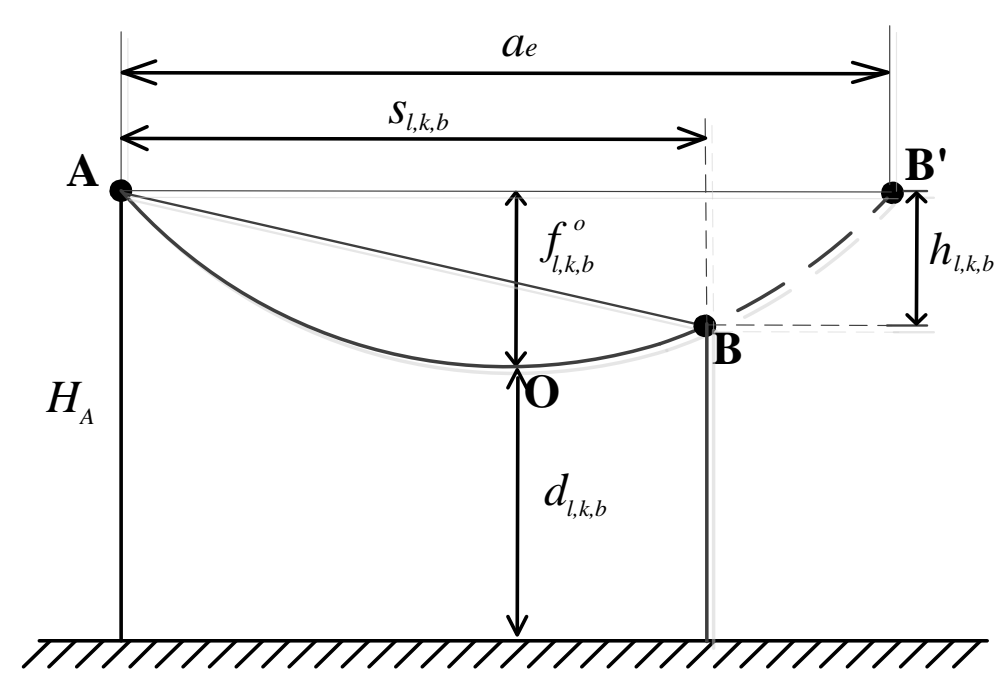

Figure 4. Relationship between the sag of lowest point and ground clearance.

From Figure 4, the minimum ground clearance of the $b$ th span of the tensioning section $k$ can be calculated by:

$$
d_{l, k, b}=H_{A}-f_{l, k, b}^{o}
$$

where $H_{A}$ is the height of the suspension point $A$. In practice, for a suspension support, $H_{A}$ can be calculated using the difference between the nominal height of the suspension support and length of the insulator set. Therefore, the ground clearance margin of the $b$ th span of the tensioning section $k$ $\left(M_{l, k, b}\right)$ can be calculated by:

$$
M_{l, k, b}=d_{l, k, b}-\eta-\delta,
$$

where $\eta$ is the specified safety clearance, $\delta$ is the specified minimum clearance safety buffer.

\section{Thermal Rating Calculation Approach for WPIOL}

The thermal ratings of the transmission lines are the important references for the lines' relay protection settings and the decision-making of the operating dispatch \& control of the power system. For a heavy loading WPIOL, the higher thermal rating is conducive to the wind power accommodation but may lead to excessive cumulative LOTS and sag. Conversely, the lower thermal rating is relatively secure but may restrict the efficient utilization of the transmission line. Therefore, an optimal thermal rating is required that can maximize the wind power accommodation while guaranteeing the acceptable sag and cumulative LOTS. 
Based on the thermal model, the LOTS model and mechanical model of the conductor, a thermal rating decision model for WPIOLs, which considers the constraints of cumulative LOTS and ground clearance is proposed to determine the thermal rating $I_{l}^{T R}$ as follows:

$$
\begin{aligned}
& \min \sum_{k=1}^{N^{H}}\left(I^{w}(k)-I_{l}^{T R}\right) \sqrt{3} U^{N} \cos \varphi, I^{w}(k)>I_{l}^{T R} \\
& \operatorname{s.t}\left\{\begin{array}{l}
F\left(I^{w}(k), T_{l}(k)\right)=0, k=1 \ldots N^{H} \\
\text { while } I^{w}(k) \geq I_{l}^{T R} \text { then } I^{w}(k)=I_{l}^{T R} \\
M_{l, k, b}\left(T_{l}(k)\right) \geq 0, k=1 \ldots N^{H}, b=1 \ldots N^{b} \\
W\left(T_{l}(k), N^{H}\right) \leq 10 \%, k=1 \ldots N^{H} \\
I_{l}^{T R} \leq \max \left(I^{w}(k)\right), k=1 \ldots N^{H}
\end{array}\right.
\end{aligned}
$$

In model (16), the objective is to minimize the cumulative curtailed MWh of wind power in $N^{H}$ hours due to the thermal rating restriction of the WPIOL $l . I^{w}(k)$ are known quantities in the model, which denotes the current generated by the wind farms at the $k$ th hour. The equality constraint represents the $\mathrm{HBE}$ of the conductor, in which $\mathrm{F}(\cdot)$ is the abbreviated expression of the heat gain and heat loss in the left side of Equation (1). Moreover, the 1st and 2nd inequality constraints represent the ground clearance constraint and cumulative LOTS constraint of the conductor, respectively; with reference to [16], the allowable LOTS was set to be $10 \%$ in this study. The 3rd inequality constraint indicates the upper bound of the decided thermal rating $\left(I_{l}^{T R}\right)$, there is no wind power curtailment when the equality holds, and the constraint can avoid the decision result of infinite thermal rating. To determine the thermal rating $I_{l}^{T R}$, a heuristic solution process for model (16) is presented as follows:

(1) Let the count variable for the cycle, $i=0$, and set the over-limit mark oflag which records the violations on the ground clearance or cumulative LOTS during the solution process is initialized to be zero. The objective is initialized to be $10^{6}$. Input the conductor type, rated voltage $\left(U^{N}\right)$ of the WPIOL, hypothetical conservative meteorological conditions, power factor $(\cos \varphi$, which was taken as 0.95 in this study), and research time horizon (number of hours). Then, calculate the thermal rating of WPIOL $l\left(I_{l}^{S T R}\right)$ under the hypothetical conservative meteorological conditions and the given MPT as the initial value of the thermal rating $\left(\right.$ let $\left.I_{l}^{T R}(i)=I_{l}^{S T R}\right)$. Prepare the wind speed data of the wind farm region during the research time horizon ( $N^{H}$ hours), and then estimate the wind power according to the power curve of wind turbine and convert the power into current under the given power factor. The wind speed data of $N^{H}$ hours can be extracted from the historical wind speed data or is generated through sampling according to a given wind speed probability density function.

(2) Let the count variable for hour, $k=1$.

(3) If $I^{w}(k) \leq I_{l}^{T R}(i)$, which indicates that the wind power curtailment is not required at the $k$ th hour, then go to the next step; if $I^{w}(k) \geq I_{l}^{T R}(i)$, which indicates that the wind power accommodation is restricted by the thermal rating of WPIOL $l$, thus resulting in wind power curtailment. Under this circumstance, the objective of model (16) is calculated and accumulated, let $I^{w}(k)=I_{l}^{T R}(i)$, then go to the next step;

(4) Calculate the temperature of the transmission line at the $k$ th hour $\left(T_{l}(k)\right)$ by using $I^{w}(k)$ and Equation (1). If $T_{l}(k) \geq T_{l}(k-1)$, set $T_{l}^{\text {flag }}=T_{l}(k)$. Calculate the cumulative LOTS rate of the conductor by using the LOTS model;

(5) Let $k=k+1$. If $k>N^{H}$, go to the next step, else return to step (3);

(6) Calculate the ground clearance of spans of WPIOL $l$ under $T_{l}^{\text {flag }}$. If violations exist on the ground clearance or cumulative LOTS, set $i=i+1$, oflag $=1$, and properly decrease $I_{l}^{T R}(i-1)$ to $I_{l}^{T R}(i)$. Then return to step (2). If there is no violation, go to the next step.

(7) If the objective is 0 , the thermal rating calculation process ends, and output $I_{l}^{T R}(i)$ as the final result. Otherwise, if the objective is not 0 and oflag $=0$, set $i=i+1$, properly increase $I_{l}^{T R}(i-1)$ 
to $I_{l}^{T R}(i)$, and return to step (2). If the objective is not 0 and oflag $=1$, the calculation ends and output $I_{l}^{T R}(i-1)$ as the final result.

Theoretically, if sufficient iterative trial calculations of the whole process with the gradually reduced trial steps in steps (6) and (7) (increase and decrease steps) of thermal rating are carried out, the heuristic approach is capable of finding the optimal thermal rating that can minimize the objective. In following case studies, to balance the calculation accuracy and the time consumption, number of iterations is selected to be three. In the first iteration, the increase and decrease steps in steps (6) and (7) are set to be $5-8 \%$ of the STR, and in the 2 nd and 3rd iterations, the steps are reduced to be about $0.5-0.8 \%$ of the STR (that is also the meaning of "properly increase" and "properly decrease" in the solution procedure). Four types of results can be obtained through this solution process, as shown in Table 3.

Table 3. Possible decision results of the LOTS model.

\begin{tabular}{ccccc}
\hline Decision Results & $\begin{array}{c}\text { Relationship of Size } \\
\text { Between } I_{l}^{T R} \text { and } I_{l}^{S T R}\end{array}$ & Objective Value & Sag Constraint & $\begin{array}{c}\text { Cumulative LOTS } \\
\text { Constraint }\end{array}$ \\
\hline 1 & $I_{l}^{T R}=I_{l}^{S T R}$ & Zero & Nonbinding & Nonbinding \\
2 & $I_{l}^{T R}>I_{l}^{S T R}$ & Zero & Nonbinding & Nonbinding \\
3 & $I_{l}^{T R}>I_{l}^{S T R}$ & Non-zero & Binding & Nonbinding \\
4 & $I_{l}^{T R}>I_{l}^{S T R}$ & Non-zero & Nonbinding & Binding \\
\hline
\end{tabular}

The first result indicates that the conventional STR is enough to fully accommodate wind power, and the thermal rating of the WPIOL does not need to be improved. The second result indicates that the thermal rating of WPIOL $l$ is improved by the proposed thermal rating calculation approach, and the wind power can be fully accommodated by the improved thermal rating. The third and fourth results indicate that the improvement of the thermal rating is restricted by the clearance and cumulative LOTS limits, respectively, and the wind power cannot be fully accommodated by the improved thermal rating. Therefore, for cases $2-4$, the proposed thermal rating approach is capable of improving the thermal rating of the WPIOL, thus conductive to wind power accommodation, and can be used to identify the restrictive factor of the thermal rating.

\section{Case Studies}

In 2012, a wind farm with 99 MW installed capacity $(66 \times 1.5 \mathrm{MW})$ was established in the Shandong Province, China. It was integrated with a power system through a $110 \mathrm{kV}$ single-circuit overhead transmission line whose conductor type is ACSR300/40 and its STR is 648.8 A (ambient temperature $35^{\circ} \mathrm{C}$, wind speed $0.5 \mathrm{~m} / \mathrm{s}$, solar insolation $1000 \mathrm{w} / \mathrm{m}^{2}$, and MPT is $80^{\circ} \mathrm{C}$ ). The maximum output current of the wind farm was estimated to be approximately $547 \mathrm{~A}$ (operating in full capacity with a power factor of 0.95 ), which was less than the STR of the WPIOL. In practice, according to the historical operational performance of the wind farm, the duration of the delivered wind power over $90 \%$ of the installed capacity is no more than $100 \mathrm{~h}$ per year. Therefore, the wind power accommodation was not restricted by the thermal rating of the WPIOL. In March 2017, a new wind farm with $66 \mathrm{MW}$ installed capacity $(33 \times 2 \mathrm{MW})$ was established next to the existing wind farm; however, the construction of the supporting WPIOL was delayed because of land expropriation problem. Under this condition, the proposed thermal rating calculation approach was implemented to improve the thermal rating of the existing WPIOL. The calculation was performed under following practical conditions:

(1) Table 4 shows the design data of the existing WPIOL, which is located on a flat area. The conservative meteorological data of the area were used (air temperature $35^{\circ} \mathrm{C}$, wind speed $0.5 \mathrm{~m} / \mathrm{s}$, and solar insolation $1000 \mathrm{w} / \mathrm{m}^{2}$ ) to calculate the temperature, LOTS, and tension \& sag of the conductor. 
(2) The historical wind power data of the past five years of the existing wind farm were used to calculated the cumulative LOTS rate of the conductor as the initial value of the percentage LOTS (2.17\%).

(3) The expected service life of the WPIOL is 30 years, and 25 years are remaining after the expansion of the wind farm. Therefore, the research time horizon was set to be 25 years and $N^{H}=25 \times 365$ $\times 24=219,000 \mathrm{~h}$.

(4) The wind power in $N^{H}$ hours was estimated by repeated use of the historical 5-year wind speed data of the wind farm area.

(5) The cut-in and cut-off wind speed of the wind turbines are 3 and $25 \mathrm{~m} / \mathrm{s}$, respectively.

(6) The safety clearance of the WPIOL is $6 \mathrm{~m}$, the length of the insulator set is $1.5 \mathrm{~m}$, and the clearance safety buffer is $1 \mathrm{~m}$.

Table 4. Design data of the WPIOL.

\begin{tabular}{|c|c|c|c|c|c|c|c|}
\hline $\begin{array}{l}\text { Number of } \\
\text { Tensioning } \\
\text { Sections }\end{array}$ & $\begin{array}{l}\text { Nominal } \\
\text { Height of Two } \\
\text { end Supports } \\
\text { (m) }\end{array}$ & $\begin{array}{l}\text { Span } \\
\text { Length } \\
\text { (m) }\end{array}$ & $\begin{array}{l}\text { Length of } \\
\text { Tensioning } \\
\text { Sections } \\
\text { (m)/Ruling } \\
\text { Span (m) }\end{array}$ & $\begin{array}{c}\text { Number of } \\
\text { Tensioning } \\
\text { Sections }\end{array}$ & $\begin{array}{l}\text { Nominal } \\
\text { Height of } \\
\text { Two end } \\
\text { Towers } \\
\text { (m) }\end{array}$ & $\begin{array}{l}\text { Span } \\
\text { Length } \\
\text { (m) }\end{array}$ & $\begin{array}{l}\text { Length of } \\
\text { Tensioning } \\
\text { Sections } \\
\text { (m)/Ruling } \\
\text { Span (m) }\end{array}$ \\
\hline \multirow{4}{*}{1} & 18,21 & 214 & $932 / 134$ & \multirow[b]{2}{*}{7} & 21,18 & 261 & \multirow{4}{*}{$1716 / 253$} \\
\hline & 21,21 & 237 & & & 18,18 & 217 & \\
\hline & 21,21 & 244 & & \multirow{7}{*}{8} & 18,18 & 242 & \\
\hline & 21,18 & 237 & & & 18,21 & 234 & \\
\hline 2 & 18,18 & 150 & $150 / 150$ & & 21,21 & 297 & \\
\hline \multirow{6}{*}{3} & 18,24 & 181 & $1194 / 200$ & & 21,18 & 208 & \\
\hline & 24,27 & 204 & & & 18,21 & 211 & \\
\hline & 27,24 & 194 & & & 21,18 & 225 & \\
\hline & 24,27 & 197 & & & 18,21 & 299 & \\
\hline & 27,21 & 224 & & \multirow{4}{*}{9} & 21,27 & 452 & $1206 / 349$ \\
\hline & 21,18 & 194 & & & 27,18 & 185 & \\
\hline \multirow{3}{*}{4} & 18,18 & 232 & $691 / 231$ & & 18,15 & 328 & \\
\hline & 18,18 & 222 & & & 15,21 & 241 & \\
\hline & 18,18 & 237 & & \multirow{2}{*}{10} & 21,21 & 307 & $550 / 280$ \\
\hline \multirow{7}{*}{5} & 18,18 & 248 & $1972 / 296$ & & 21,21 & 243 & \multirow{6}{*}{$1160 / 244$} \\
\hline & 18,21 & 347 & & \multirow{5}{*}{11} & 21,21 & 223 & \\
\hline & 21,24 & 245 & & & 21,24 & 292 & \\
\hline & 24,21 & 335 & & & 24,21 & 204 & \\
\hline & 21,24 & 338 & & & 21,21 & 172 & \\
\hline & 21,18 & 252 & & & 21,21 & 269 & \\
\hline & 18,18 & 207 & & \multirow{2}{*}{12} & 21,18 & 241 & $529 / 268$ \\
\hline \multirow{2}{*}{6} & 18,24 & 227 & $486 / 245$ & & 18,21 & 288 & \\
\hline & 24,18 & 259 & & \multirow{3}{*}{13} & 21,27 & 347 & $642 / 277$ \\
\hline \multirow{3}{*}{7} & 18,18 & 210 & $1178 / 239$ & & 21,27 & 186 & \\
\hline & 18,18 & 268 & & & 27,21 & 109 & \\
\hline & 18,21 & 222 & & 14 & 21,15 & 227 & $227 / 227$ \\
\hline
\end{tabular}

According to above conditions, thermal rating was calculated through the procedure presented in Section 2. Partial results of the thermal rating calculation process are shown in Table 5 and Figure 4. 
Table 5. Partial results of the thermal rating calculation process.

\begin{tabular}{ccccc}
\hline $\begin{array}{c}\text { Thermal Rating } \\
\text { (A) }\end{array}$ & $\begin{array}{c}\text { Maximum } \\
\text { Operational } \\
\text { Temperature }\left({ }^{\circ} \mathbf{C}\right)\end{array}$ & $\begin{array}{c}\text { Minimum } \\
\text { Clearance } \\
\text { Margin (m) }\end{array}$ & $\begin{array}{c}\text { Percentage of } \\
\text { Cumulative } \\
\text { LOTS (\%) }\end{array}$ & $\begin{array}{c}\text { Cumulative Wind } \\
\text { Power Curtailment } \\
\text { (MWh) }\end{array}$ \\
\hline 648.8 & 80.0 & 2.19 & 5.78 & $5.13 \times 10^{5}$ \\
700 & 86.6 & 1.93 & 6.68 & $2.93 \times 10^{5}$ \\
750 & 93.7 & 1.66 & 7.79 & $1.30 \times 10^{5}$ \\
800 & 101.5 & 1.36 & 9.02 & $1.02 \times 10^{3}$ \\
840 & 108.3 & 1.1 & 9.55 & 1.56 \\
845 & 108.7 & 1.08 & 9.56 & 0 \\
\hline
\end{tabular}

As shown in Table 5, if the conventional STR (648.4 A) is applied, the corresponding maximum operating temperature of conductor is $80^{\circ} \mathrm{C}$, which is the same as the MPT and causes the lowest sag and cumulative LOTS compared with other thermal ratings but the highest wind power curtailment. As shown in Figure 5, with the increase in thermal rating, the increasing operating temperature increases the sag (the decreasing clearance margin) as well as cumulative LOTS of the conductor, and the wind power curtailment is reduced. Finally, when the thermal rating is increased to $845 \mathrm{~A}$, the ground clearance and cumulative LOTS of conductor are still within their limits (see Table 5), and the objective value is 0 . Therefore, this case belongs to the second type of result in Table 3 , and the thermal rating is finally improved from 648.4 to $845 \mathrm{~A}$. The improvement may be different for different overhead lines, as it depends on the reserved design margin of ground clearance. In practice, the designers have autonomies to appropriately reserve design margin of ground clearances (1-2 m, in China) to conservatively accommodate the possible degradation of the design error and the ground surface condition in the future. Theoretically, the more the design margin is reserved, the more thermal rating can be improved, if the thermal rating improvement is limited by the ground clearance. Adversely, the improvement can be zero in the extreme circumstances that the ground clearances of spans under the MPT are designed to exactly reach the specified safe clearance.

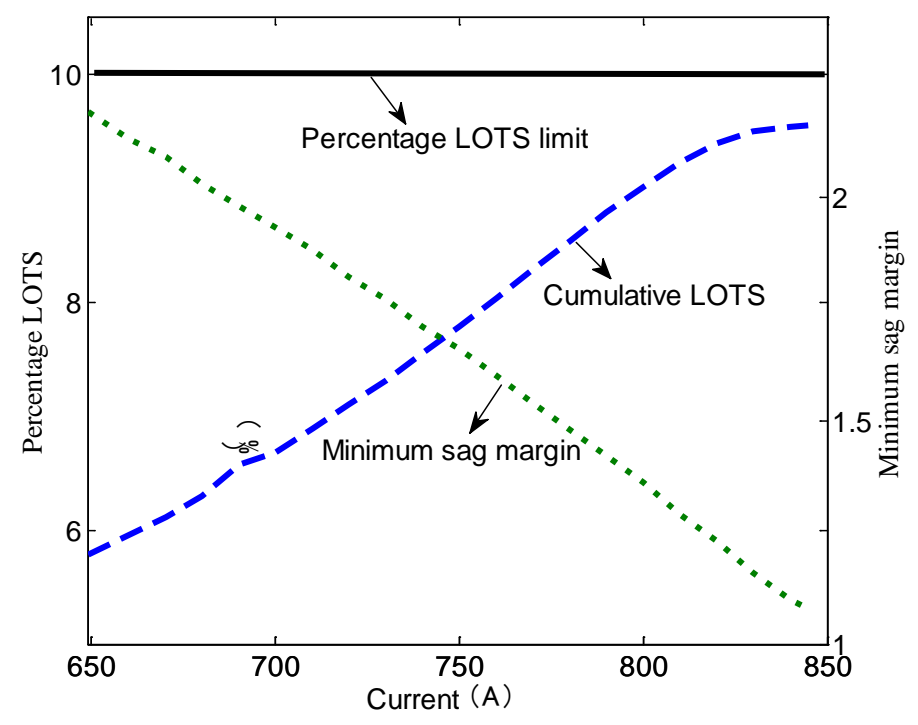

Figure 5. Changing curves of cumulative LOTS and clearance margin with the varying thermal ratings of the conductor.

Different wind speed probability density functions (pdfs) were used to further testify the validity of the proposed thermal rating calculation approach. Based on the previous specified conditions, supposing the wind speed of the wind farm site is Rayleigh distributed, then Figure 6 shows the curves of pdfs with varying scale parameters $(c)$, including $c=4$ (the corresponding average wind speed is 
$3.55 \mathrm{~m} / \mathrm{s}$ ), $c=6$ (the average wind speed is $5.32 \mathrm{~m} / \mathrm{s}$ ) and $c=8$ (the average wind speed is $7.09 \mathrm{~m} / \mathrm{s}$ ). Table 6 shows the thermal rating calculation results for the three wind speed pdfs.

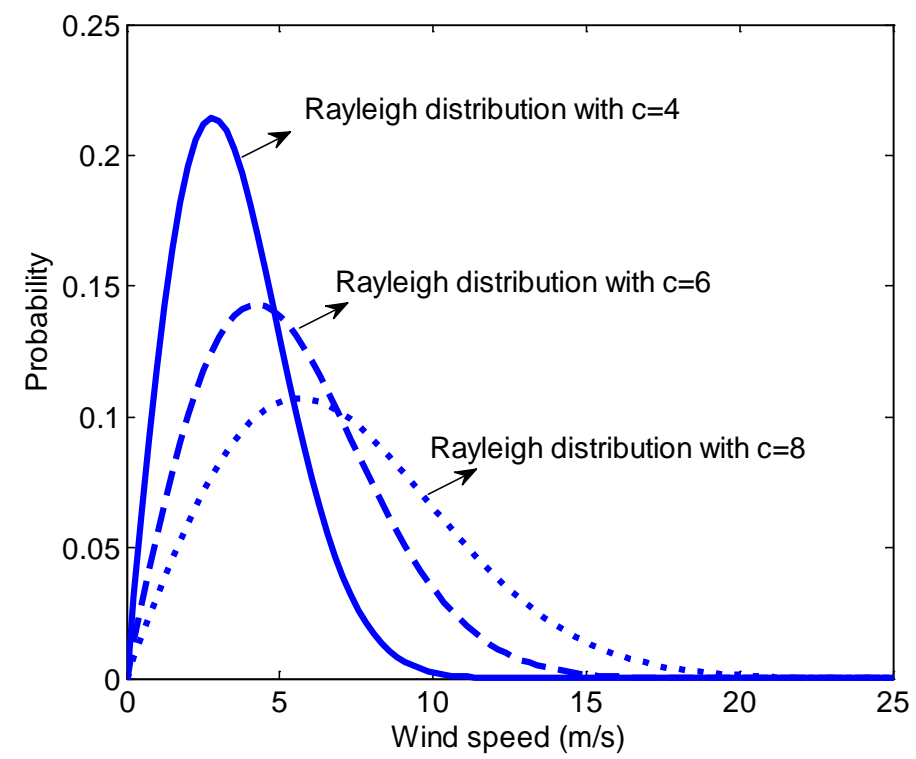

Figure 6. Rayleigh pdf with different scale parameter $c$.

Table 6. Calculation result of thermal rating for Rayleigh distributed wind speed with $c=8$.

\begin{tabular}{|c|c|c|c|c|c|c|c|c|}
\hline $\begin{array}{l}\text { Thermal } \\
\text { Rating } \\
\text { (A) }\end{array}$ & $\begin{array}{l}\text { Maximum } \\
\text { Operational } \\
\text { Temperature } \\
\left({ }^{\circ} \mathrm{C}\right)\end{array}$ & $\begin{array}{l}\text { Minimum } \\
\text { Sag } \\
\text { Margin } \\
\text { (m) }\end{array}$ & $\begin{array}{l}\begin{array}{c}\text { Percentage } \\
\text { of } \\
\text { Cumulative }\end{array} \\
\text { LOTS (\%) }\end{array}$ & $\begin{array}{l}\text { Wind } \\
\text { Power } \\
\text { Curtailment } \\
\text { (MWh) }\end{array}$ & $\begin{array}{l}\begin{array}{l}\text { Percentage } \\
\text { of }\end{array} \\
\text { Cumulative } \\
\text { LOTS }(\%)\end{array}$ & $\begin{array}{l}\text { Wind } \\
\text { Power } \\
\text { Curtailment } \\
\text { (MWh) }\end{array}$ & $\begin{array}{c}\begin{array}{c}\text { Percentage } \\
\text { of }\end{array} \\
\text { Cumulative } \\
\text { LOTS }(\%)\end{array}$ & $\begin{array}{l}\text { Wind } \\
\text { Power } \\
\text { Curtailment } \\
\text { (MWh) }\end{array}$ \\
\hline & & & \multicolumn{2}{|c|}{$c=4$} & \multicolumn{2}{|c|}{$c=6$} & \multicolumn{2}{|c|}{$c=8$} \\
\hline 648.8 & 80.0 & 1.49 & 3.47 & 8677.5 & 4.92 & 426,000 & 6.31 & $1,708,800$ \\
\hline 690 & 85.2 & 1.28 & 3.52 & 6113.3 & 5.48 & 335,110 & 7.27 & $1.39 \times 10^{6}$ \\
\hline 730 & 90.8 & 1.07 & 3.59 & 4197.4 & 6.22 & 257,000 & 8.47 & $1,098,500$ \\
\hline 770 & 96.7 & 0.84 & 3.70 & 2763.3 & 7.20 & 187,360 & 10.0 & 825,430 \\
\hline 810 & 103.1 & 0.59 & 3.86 & 1685.2 & 8.51 & 124,920 & - & - \\
\hline 847 & 109.5 & 0.35 & 4.14 & 834.7 & 10.0 & 72,761 & - & - \\
\hline 898 & 118.7 & 0.00 & 4.62 & 147.1 & - & - & - & - \\
\hline
\end{tabular}

As shown in Table 6, the thermal rating of the WPIOL tends to decrease with the increasing scale parameter $c$, which is proportional to the average wind speed. When $c=4$, the sag margin of the 3th span in the 9th tensioning section first reaches 0 when the thermal rating increases to $898 \mathrm{~A}$. Although the operating temperature of the conductor reaches $118.7^{\circ} \mathrm{C}$ at this thermal rating, the cumulative time of the elevated temperature is much shorter than the larger-scale parameters, thus yielding a much smaller cumulative LOTS (4.62\%). Therefore, the thermal rating is limited by the safe clearance in this case and can be further improved by heightening the normal height of the suspension towers of the critical span. Therefore, this case belongs to the third result in Table 3 , and the thermal rating is finally improved from 648.4 to $898 \mathrm{~A}$.

When $c=6$ and 8 , the better wind resources aggravate the loading level of the WPIOL in most cases, entailing greater cumulative LOTS; thus the thermal rating of WPIOL decreases because of the LOTS restriction. Therefore, cases $c=6$ and 8 belong to the fourth result in Table 3, and the thermal rating is finally improved from 648.4 to $847 \mathrm{~A}$ and $770 \mathrm{~A}$, respectively.

Note that the conventional MPT is no longer used here to calculate thermal ratings; conversely, the reachable maximum operating temperature of the conductor is also decided by model (16). Moreover, the thermal rating of the WPIOL can be significantly improved by the proposed thermal 
rating calculation approach compared with the conventional STR under a wide variation range of the average wind speed; this further demonstrates the adaptability of the approach for the WPIOLs.

\section{Conclusions}

This paper presents a new thermal rating calculation approach for WPIOLs. The following conclusions can be drawn.

(1) The sag and cumulative LOTS restrictions of the conductor are introduced to formulate a thermal rating decision model for WPIOLs. The model is capable of deciding a thermal rating by considering essential restrictions on the thermal transfer capability of the conductor by avoiding the conservative setting of the MPT for conductors, thus improving the thermal rating and utilization efficiency of WPIOLs.

(2) A heuristic solution approach was proposed for the proposed model. It can not only find the optimized thermal rating but also provide the restrictive factor of the thermal rating promotion. In addition, the solution approach has advantages in terms of high reliability and practicability.

(3) The thermal rating decided by the model was improved securely because the conservative meteorological conditions were used. Moreover, the decided thermal rating can be used for a life-time similar to the conventional STR; this is beneficial for the utilization of power system operators.

Author Contributions: Conceptualization, M. W. and M. W.; Methodology, J.H. (Jinxin Huang) and Z. J.; Software, J.H. (Jinyan Huang); Resources, Z. J. and J.H. (Jinyan Huang); Validation, J.H. (Jinyan Huang) and Z. J.; Writing-Original Draft Preparation, M. W. and M. W.; Writing-Review \& Editing, M. W. and J.H. (Jinxin Huang).

Acknowledgments: The authors would like to express appreciation to national nature science foundation, Grant 51407111 and 51407106, for supporting this research.

Conflicts of Interest: The authors declare no conflict of interest.

\section{Nomenclature}

\section{(A) Parameters}

A

$C_{p}$

$D_{w}$

$D_{0}$

E

$m_{\mathcal{c}} g$

$N^{H}$

$N^{b}$

$N^{w}$

$R_{l}^{r e f}$

$s_{l, k, b}$

$s_{l, k}^{r}$

$t$

$T_{l}^{r e f}$

$T_{l}^{a m b}(t)$

$\rho$

$\chi_{i}$

$\alpha$

$\beta$

$\varepsilon$
Conductor cross section of WPIOL $l\left[\mathrm{~mm}^{2}\right]$.

Overall efficiency of wind turbines.

Diameter of the aluminum wires [mm].

Diameter of the draw rod [mm].

Modulus of elasticity [N/ $\left.\mathrm{mm}^{2}\right]$.

Per unit length weight of conductor $[\mathrm{kg} / \mathrm{m}]$.

Number of hours in research time horizon.

Number of spans in tensioning section $k$.

Number of wind turbines in wind farm.

Per unit length resistance of WPIOL $l$ at the reference temperature $[\Omega / \mathrm{m}]$.

Length of the $b$-th span in the $k$ th tensioning section of WPIOL $l[\mathrm{~m}]$.

Ruling span of the $k$-th tensioning section of WPIOL $l[\mathrm{~m}]$.

time [s].

Reference temperature of WPIOL $l\left(20^{\circ} \mathrm{C}\right)\left[{ }^{\circ} \mathrm{C}\right]$.

Ambient temperature of WPIOL $l$ at time $t\left[{ }^{\circ} \mathrm{C}\right]$.

Air density $\left[\mathrm{kg} / \mathrm{m}^{3}\right]$.

Rotor area of the wind turbine $i\left[\mathrm{~m}^{2}\right]$.

Resistance-temperature coefficient of conductor $\left[\Omega /{ }^{\circ} \mathrm{C}\right]$.

Solar absorptivity of conductor.

Thermal expansion coefficient of conductor $\left[\mathrm{m} /{ }^{\circ} \mathrm{C}\right]$. 


\section{(B) Variables}

$I_{l}(t)$

$I_{l}(i)$

$I_{l}^{T R}$

$I_{l}^{S T R}$

$T_{l}(t)$

$T_{l}(i)$

$T_{l, k}^{(m)}$

$T_{l, k}^{(0)}$

$W$

$W(i)$
Current of WPIOL $l$ at time $\mathrm{t}$ [A].

Current of WPIOL $l$ at the $i$-th hour [A].

Thermal rating of WPIOL $l$.

Static thermal rating of WPIOL $l$.

Temperature of WPIOL $l$ at time $t\left[{ }^{\circ} \mathrm{C}\right]$.

Temperature of WPIOL $l$ at the $i$-th hour $\left[{ }^{\circ} \mathrm{C}\right]$.

Temperature of the $k$-th tensioning section of the WPIOL $l$ at state $m\left[{ }^{\circ} \mathrm{C}\right]$.

Temperature of the $k$-th tensioning section of the WPIOL $l$ at the initial state $\left[{ }^{\circ} \mathrm{C}\right]$.

Percentage LOTS [\%].

Percentage LOTS at the $i$ th hour [\%].

\section{References}

1. Lingzhi, Z.; Ning, C.; Hualing, H. Key problem and solutions of wind power accommodation. Autom. Electr. Power Syst. 2011, 35, 29-34.

2. Dewei, L.; Yuehui, H.; Wang, W.; Guo, J. Analysis on provincial system available capability of accommodating wind power considering peak load dispatch and transmission constraints. Autom. Electr. Power Syst. 2011, 35, 77-81.

3. Gang, M.U.; CUIYang, L.; Gangui, Y.A.N.; Taiyi, Z.H.E.N.G.; Guangxin, X.U. Source-Grid coordinated dispatch method for transmission constrained grid with surplus wind generators. Autom. Electr. Power Syst. 2013, 37, 24-29.

4. Qinglai, G.; Bin, W.; Hongbin, S. Autonomous-Synergic voltage control technology supporting large-scale wind power integration. Autom. Electr. Power Syst. 2015, 39, 88-93.

5. Seppa, T.O. A practical approach for increasing the thermal capabilities of transmission lines. IEEE Trans. Power Deliv. 1993, 8, 1536-1542. [CrossRef]

6. Wan, H.; McCalley, J.D.; Vittal, V. Increasing thermal rating by risk analysis. IEEE Trans. Power Syst. 1999, 14, 815-821. [CrossRef]

7. Smolleck, H.A.; Sims, J.P. Guidelines for the selection and operation of bare ACSR conductors with regard to current carrying capacity. Electr. Power Syst. Res. 1982, 5, 179-190. [CrossRef]

8. GB 50545-2010[S]. Design Standard for 110 kV 750 kV Overhead Transmission Lines. Available online: https:/ / zhidao.baidu.com/share/408d149d40302dcf47a1c7f56d183d4d.html (accessed on 4 May 2018).

9. McElvain, F.R.; Mulnix, S.S. Statistically determined static thermal ratings of overhead high voltage transmission lines in the rocky mountain region. IEEE Trans. Power Syst. 2000, 15, 899-902. [CrossRef]

10. Murray, D.W. A new thermal rating approach: The real time thermal rating system for strategic overhead conductor transmission lines-Part I: General description and justification of the real time thermal rating system. IEEE Trans. Power Appar. Syst. 1977, 96, 803-809.

11. Dawson, L.; Knight, A.M. Applicability of Dynamic Thermal Line Rating for Long Lines. IEEE Trans. Power Deliv. 2018, 33, 719-727. [CrossRef]

12. Teh, J.; Cotton, I. Reliability impact of dynamic thermal rating system in wind power integrated network. IEEE Trans. Reliab. 2016, 65, 1081-1089. [CrossRef]

13. Ringelband, T.; Lange, M.; Dietrich, M. Potential of improved wind integration by dynamic thermal rating of overhead lines. In Proceedings of the IEEE PowerTech Meeting, Bucharest, Rumania, 28 June-2 July 2009; pp. 1-5.

14. Kazerooni, A.K.; Mutale, J.; Perry, M.; Venkatesan, S. Dynamic thermal rating application to facilitate wind energy integration. In Proceedings of the IEEE PowerTech Meeting, Trondheim, Norway, 19-23 June 2011.

15. Wallnerstrom, C.J.; Huang, Y.; Soder, L. Impact from dynamic line rating on wind power integration. IEEE Trans. Smart Grid 2015, 6, 343-350. [CrossRef]

16. Sugihara, H.; Funaki, T.; Yamaguchi, N. Evaluation method for real-time dynamic line ratings based on line current variation model for representing forecast error of intermittent renewable generation. Energies 2017, 10, 503. [CrossRef] 
17. Douglass, D.; Chisholm, W.; Davidson, G.; Grant, I.; Lindsey, K.; Lancaster, M.; Lawry, D.; McCarthy, T.; Nascimento, C.; Pasha, M.; et al. Real-time overhead transmission line monitoring for dynamic rating. IEEE Trans. Power Deliv. 2016, 31, 921-927. [CrossRef]

18. Bucher, M.A.; Andersson, G. Robust corrective control measures in power systems with dynamic line rating. IEEE Trans. Power Syst. 2016, 31, 2034-2043. [CrossRef]

19. Adomah, K.; Mizuno, Y.; Naito, K. Probabilistic assessment of the reduction in tensile strength of an overhead transmission line's conductor with reference to climatic data. IEEE Trans. Power Deliv. 2000, 15, 1221-1224. [CrossRef]

20. CIGRE, W. Thermal behavior of overhead conductors. Electra 1992, 144, 107-125.

21. Arroyo, A.; Castro, P.; Martinez, R.; Manana, M.; Madrazo, A.; Lecuna, R.; Gonzalez, A. Comparison between IEEE and CIGRE thermal behaviour standards and measured temperature on a 132-kV overhead power line. Energies 2015, 8, 13660-13671. [CrossRef]

22. Morgan, V.T. The loss of tensile strength of hard-drawn conductors by annealing in service. IEEE Trans. Power Syst. 1979, 98, 700-709. [CrossRef]

23. Morgan, V.T. Effect of elevated temperature operation on the tensile strength of overhead conductors. IEEE Trans. Power Deliv. 1996, 11, 345-351. [CrossRef]

24. Kiessling, F.; Nefzger, P.; Nolasco, J.F.; Kaintzyk, U. Overhead Power Lines: Planning, Design, Construction; Springer: Berlin, Germany, 2003.

(C) 2018 by the authors. Licensee MDPI, Basel, Switzerland. This article is an open access article distributed under the terms and conditions of the Creative Commons Attribution (CC BY) license (http://creativecommons.org/licenses/by/4.0/). 